\title{
Prenatal Malnutrition Leads to Deficits in Attentional Set Shifting and Decreases Metabolic Activity in Prefrontal Subregions that Control Executive Function
}

\author{
Jill A. McGaughy ${ }^{a} \quad$ Ana C. Amaral ${ }^{b} \quad$ R. Jarrett Rushmore ${ }^{b}$ David J. Mokler ${ }^{d}$ \\ Peter J. Morgane ${ }^{d}$ Douglas L. Rosene ${ }^{b}$ Janina R. Galler ${ }^{c}$ \\ ${ }^{a}$ Department of Psychology, University of New Hampshire, Durham, N.H., ${ }^{b}$ Department of Anatomy and Neurobiology, Boston \\ University Medical Campus, and 'Judge Baker Children's Center, Harvard Medical School, Boston, Mass., and ' Department of \\ Biomedical Sciences, University of New England, Biddeford, Maine., USA
}

\section{Key Words}

Cognitive control · Anterior cingulate cortex · Prelimbic cortex Orbitofrontal cortex $\cdot{ }^{14} \mathrm{C}$-2-deoxyglucose

\begin{abstract}
Globally, over $25 \%$ of all children under the age of 5 years experience malnutrition leading to cognitive and emotional impairments that can persist into adulthood and beyond. We use a rodent model to determine the impact of prenatal protein malnutrition on executive functions in an attentional set-shifting task and metabolic activity in prefrontal cortex (PFC) subregions critical to these behaviors. Long-Evans dams were provided with a low (6\% casein) or adequate ( $25 \%$ casein) protein diet 5 weeks before mating and during pregnancy. At birth, the litters were culled to 8 pups and fostered to control dams on the $25 \%$ casein diet. At postnatal day 90 , prenatally malnourished rats were less able to shift attentional set and reverse reward contingencies than controls, demonstrating cognitive rigidity. Naive same-sexed littermates were assessed for regional brain activity using the metabolic marker ${ }^{14} \mathrm{C}$-2-deoxyglucose (2DG). The prenatally malnourished rats had lower metabolic activity than controls in prelimbic, infralimbic, anterior cingulate, and orbitofrontal cortices, but had comparable activity in the nearby
\end{abstract}

piriform cortex and superior colliculus. This study demonstrates that prenatal protein malnutrition in a well-described animal model produces cognitive deficits in tests of attentional set shifting and reversal learning, similar to findings of cognitive inflexibility reported in humans exposed to early childhood malnutrition.

(c) 2014 S. Karger AG, Basel

\section{Introduction}

Childhood malnutrition impacts $26 \%$ of children under the age of 5 years worldwide [1], leading to cognitive and behavioral deficits $[2,3]$. These deficits, broadly characterized as affecting executive function, include attention deficits and impairments on continuous performance tasks. Effects have been documented longitudinally up to 40 years after the childhood malnutrition episode [4-6]. In this cohort, parent, teacher and self-report behavior questionnaires of attentional impairments [6], including cognitive rigidity, have been confirmed by impaired performance on tests of attentional set shifting [7],

P.J. Morgane died on September 27, 2010.

\section{KARGER}

E-Mail karger@karger.com

www.karger.com/dne
(C) 2014 S. Karger AG, Basel

0378-5866/14/0366-0532\$39.50/0
J.A. McGaughy

Department of Psychology

University of New Hampshire

Durham, NH 03824 (USA)

E-Mail j.mcgaughy@unh.edu 
Table 1. Animal model of prenatal malnutrition

\begin{tabular}{lllll}
\hline Prenatal nutrition & $\begin{array}{l}\text { Before mating } \\
(5 \text { weeks })\end{array}$ & $\begin{array}{l}\text { Pregnancy } \\
(3 \text { weeks })\end{array}$ & Birth & $\begin{array}{l}\text { After birth } \\
(\text { PND 0-21) }\end{array}$ \\
\hline $\begin{array}{l}\text { Low protein }(6 / 25) \\
\text { Adequate protein }(25 / 25)\end{array}$ & $\begin{array}{l}\frac{6 \% \text { casein }}{25 \% \text { casein }} \\
25 \% \text { casein }\end{array}$ & $\begin{array}{l}\frac{6 \% \text { casein }}{25 \% \text { casein }} \\
\text { Foster mothers }\end{array}$ & \begin{tabular}{l}
$25 \%$ casein \\
\hline
\end{tabular}
\end{tabular}

All pups were fostered (as whole litters, culled to 8 pups) at birth (PND 0) to well-nourished mothers, as indicated by the underlining and italic font.

with the Wisconsin Card Sorting Task (WCST). In both human and animal models, executive function has also been shown to be sensitive to other nutritional insults such as iron deficiency [8], which affects the integrity of the prefrontal cortices (PFC) [9], the region reported as most closely associated with executive function in humans [10-12] and animals [13-15]. Although prenatal protein malnutrition is also known to impact the anatomy and function of the PFC $[16,17]$, studies on executive functioning in animal models of malnutrition during early development are limited.

In the current study, we use a rat model of prenatal protein malnutrition that has been extensively tested in our laboratory $[18,19]$ to investigate the specificity of the attentional impairments produced by prenatal malnutrition. We used an intradimensional/extradimensional (ID/ ED) set-shifting task that allows the functional dissociation of prefrontal subregions, including the anterior cingulate cortex (ACC) [20,21], lateral orbitofrontal cortex (OFC) [22] and prelimbic cortex (PrL) [15] to assess the effects of prenatal malnutrition. The ED shift task has cognitive demands identical to those of the WCST, but the ID/ED was designed to improve sensitivity to frontal lobe dysfunction, limit sensitivity to dysfunction in nonfrontal regions and better elucidate the underlying cognitive impairments associated with failures in attentional set shifting $[10,11]$. The ID/ED task utilized here also assesses the ability of subjects to perform simple sensory discriminations, disregard irrelevant information, learn that reinforcement contingencies have changed and form an attentional set. To determine how prenatal malnutrition impacts the metabolic activity in the prefrontal subregions hypothesized to mediate performance in this attentional set-shifting task, naive male littermates (siblings) of the behaviorally characterized subjects were injected with ${ }^{14} \mathrm{C}$-2-deoxyglucose (2DG) as a marker of neuronal activity. Uptake of 2DG in prenatally protein malnourished rats was then compared to controls. Previous work has shown that rats with poor executive control have lower metabolic activity in prefrontal subregions [23]. We hypothesized that prenatal malnutrition would produce cognitive rigidity and that metabolic activity in prefrontal regions critical to executive function would be reduced in prenatally malnourished rats relative to controls.

\section{Methods}

\section{Subjects and Housing Conditions}

Long-Evans hooded rats were obtained from Charles River (Wilmington, Mass., USA). They were housed in animal quarters maintained at a temperature of $23^{\circ} \mathrm{C}\left( \pm 2^{\circ}\right)$ and at $45-55 \%$ humidity with a reverse 12-hour night (8:00-20:00), 12-hour day (20:008:00) light cycle. Behavioral testing occurred during the dark phase of the cycle between 9:00 and 13:00 6 days per week, enabling observations during the active waking period of the rat. Red fluorescent lighting during the dark phase of the cycle provided continuous dim illumination for animal care and testing. All procedures described in this paper were approved by the University of New England Institutional Animal Care and Use Committee (protocol $20101005 \mathrm{MOK})$ in accordance with guidelines outlined in the NIH Guide for the Care and Use of Laboratory Animals and the Society for Neuroscience Policies on the Use of Animals and $\mathrm{Hu}$ mans in Neuroscience Research.

\section{Nutritional Treatment and Breeding}

Virgin female Long-Evans hooded rats were randomly assigned to one of two nutritional conditions. One group was fed a high protein diet (25\% casein, Teklad; Harlan Laboratories, Madison, Wisc., USA) while the other group received an isocaloric, low protein diet ( $6 \%$ casein, Teklad) beginning 5 weeks prior to mating and continuing throughout pregnancy. These diets have been described in detail elsewhere [24-27]. All females were mated with males that had been acclimated to the same respective diet for 1 week. Throughout pregnancy, the dams were singly housed in individual polysulfone breeding cages, $39.5 \times 34.6 \times 21.3 \mathrm{~cm}$ (Tecniplast, Maywood, N.J., USA). Following parturition, litters from both nutritional groups were culled to 8 pups ( 2 females and 6 males) and fostered as whole litters within $24 \mathrm{~h}$ of birth to dams receiving the $25 \%$ casein diet (table 1). Each foster dam had given birth within the same 24-hour period. Pups born to mothers on the $6 \%$ casein diet that were fostered to mothers on the $25 \%$ casein diet 
were designated as members of the $6 / 25$ (prenatally malnourished) group while pups born to mothers on a $25 \%$ casein diet that were also fostered to other mothers on a $25 \%$ casein diet were designated as members of the 25/25 (prenatally well-nourished) group and served as control subjects. On postnatal day (PND) 21, all rats were weaned and placed on a standard laboratory chow diet (Formula 5001; Purina Mills Inc., Richmond, Ind., USA). The subjects were then pair-housed with same-sexed littermates and given food and water ad libitum. Personnel involved in behavioral and 2DG studies were blinded to condition until the completion of data collection. The rats were weighed weekly during the litter period and after weaning.

\section{Behavioral Subjects}

One male rat from each of ten 6/25 litters and seventeen 25/25 litters served as subjects. Rats assigned to behavioral testing were moved to single housing in polysulphonate microisolator cages (Tecniplast Inc.), and food restriction was initiated on PND 90. Beginning 1 week prior to and throughout behavioral testing, subjects received $18 \mathrm{~g}$ of standard rat chow daily with access to water ad libitum. This allowed subjects to maintain weights that were approximately $90 \%$ of those of the age-matched controls. All animals were weighed weekly to assure healthy weights were maintained.

\section{Behavioral Apparatus and Test Procedures}

Training and testing procedures have been described in detail [28] and so are briefly described here. All training and testing was completed in a plastic testing box $(88 \times 42 \times 30 \mathrm{~cm}$; Sterilite Corp., Townsend, Mass., USA). Test stimuli were placed in either end of the box with access between these sections restricted by a removable divider, while stimuli were placed in the distal end of the box. A food pellet (Bio-Serv precision pellet, $45 \mathrm{mg}$; Research Diets, Frenchtown, N.J., USA) concealed in a small terracotta flower pot served as reinforcement for both training and testing phases. For all stages of training and testing, the unbaited pot contained an equal, but crushed, amount of reinforcer to prevent the rats from using the scent of the reinforcer to identify the correct stimuli.

Day 1: Shaping. Methods are similar to those described in previous work $[20,28,29]$. First, the rats were trained to dig for reinforcement in weighted terracotta pots (height of $10 \mathrm{~cm}$, internal diameter of $10.2 \mathrm{~cm}$ ) that were affixed to the floor of the testing box with velcro (Manchester, N.H., USA). The rats were placed behind the divider in the testing box with an unscented terracotta pot filled with pine chip bedding on the other side of the divider. This allowed the experimenter to control the rat's access to the stimuli. A stopwatch was begun after the removal of the divider and response latency was recorded after the animal displaced digging media in the pot using either its paw or nose. The rat was given $90 \mathrm{~s}$ (limited hold) to retrieve the reinforcer. After the retrieval of the reinforcer or the expiration of the $90 \mathrm{~s}$ limited hold, the pot was removed from the box. The rat was again placed behind the divider while the pot was placed in the testing box. The position of the pot was varied randomly from right to left within the testing area to prevent the development of response bias based on the position of reinforcement. After the animal readily retrieved 10 unburied rewards, the reinforcer was buried at increasing depths. Shaping was stopped when the rat recovered 10 consecutive, fully buried reinforcers with its forepaw. On this and all other procedures, the number of daily trials was not capped, but sessions were terminated if the rat made 12 consecutive omissions and training resumed the following day.

Day 2: Exemplar Training. After shaping to dig for reward, the rats were given a series of conditional discriminations that exposed the animals to the types of stimuli to be tested in the ID/ED task: odor, digging media and texture. Exemplars for each of the three dimensions were as follows: (1) digging media: shredded green tissue paper versus shredded white tissue paper, (2) texture: white fake fur with $1.25-\mathrm{cm}$ pile versus the reverse side of the fur covered the outside of the pots and (3) odor: pine versus mulberry. In the case of odor and texture discriminations, both pots were filled with shredded manila folder to hide the reinforcer. Stimuli used here were not used again in later stages of the task. The order of exemplar training was counterbalanced across subjects. These discriminations trained the rats that each of the stimulus modalities may predict reinforcement and allowed the assessment of basic sensory discrimination abilities.

For each stage of training and testing beyond shaping, the animal was allowed 4 discovery trials with a 90 -second limited hold. If the animal dug in the incorrect pot during these discovery trials, an incorrect response and latency were recorded. To facilitate learning, the subject was allowed to switch its search to the correct pot and receive reinforcement prior to the expiration of the limited hold. Response latencies were recorded as the amount of time between the removal of the divider and when the rat displaced digging media in the first pot with its forepaw. After the completion of these discovery trials, the limited hold was reduced to $60 \mathrm{~s}$. If the rat dug in the incorrect pot during a nondiscovery trial, the trial was terminated to prevent access to the correct pot. An incorrect choice and response latency were recorded. If the animal failed to respond within the limited hold, the trial was marked an omission. Trials were continued for each test until the criterion level of 6 consecutive, correct responses was made. The stimuli were removed after a response or expiration of the limited hold.

\section{Behavioral Testing}

Day 3: ID/ED Set-Shifting Task. After exemplar training, the rats began testing in the ID/ED task which consisted of the following subtests: simple discrimination (SD), compound discrimination (CD) and ID and ED tests. There were also three reinforcement reversals, one each after the CD, ID and ED tests; these were designated as the CDR, IDR and EDR, respectively, which test inhibitory control. For all tests, the outer surface of the pots was covered with textures and the inside of the pots was filled with digging media that was scented using diluted aromatherapy oils (essential oils diluted 1:100 in vegetable oil).

The SD tested a conditional discrimination between pots that differed on only one of the three dimensions (odor, digging media or texture). For example, in a test of odor discrimination, a pot scented with cinnamon+ (the plus sign indicates the reinforced stimulus) was baited with an intact reinforcer and presented simultaneously with a pot scented with patchouli containing an equal amount of crushed reinforcer. Table 2 provides examples of the stimuli used.

In the $\mathrm{CD}$ test, the rewarded attribute remained consistent, e.g. odor, but the pots differed on two dimensions rather than one. This stage of testing assesses susceptibility to distraction. All test stimuli had one dimension that was present and remained constant across a set of test stimuli (e.g. texture). Testing was done with alternate pairs of stimuli to train subjects to focus attention 
Table 2. Summary of attentional set-shifting task stimuli

\begin{tabular}{|c|c|c|c|}
\hline & Testing pair 1 & Testing pair 2 & Never relevant attribute \\
\hline $\mathrm{SD}$ & $\begin{array}{l}\text { Cinnamon/light shapes+ } \\
\text { vs. patchouli/light shapes }\end{array}$ & $\begin{array}{l}\text { Cinnamon/dark shapes+ } \\
\text { vs. patchouli/dark shapes }\end{array}$ & \\
\hline $\mathrm{CD}$ & $\begin{array}{l}\text { Cinnamon/light shapes+ } \\
\text { vs. patchouli/dark shapes }\end{array}$ & $\begin{array}{l}\text { Cinnamon/dark shapes+ } \\
\text { vs. patchouli/light shapes }\end{array}$ & Velour \\
\hline CDR & $\begin{array}{l}\text { Patchouli/light shapes+ } \\
\text { vs. cinnamon/dark shapes }\end{array}$ & $\begin{array}{l}\text { Patchouli/dark shapes+ } \\
\text { vs. cinnamon/light shapes }\end{array}$ & Velour \\
\hline ID shift & $\begin{array}{l}\text { Lilac/white buttons+ } \\
\text { vs. rose/black buttons }\end{array}$ & $\begin{array}{l}\text { Lilac/black buttons+ } \\
\text { vs. rose/white buttons }\end{array}$ & Corduroy \\
\hline IDR & $\begin{array}{l}\text { Rose/white buttons+ } \\
\text { vs. lilac/black buttons }\end{array}$ & $\begin{array}{l}\text { Rose/black buttons+ } \\
\text { vs. lilac/white buttons }\end{array}$ & Corduroy \\
\hline ED shift & $\begin{array}{l}\text { Colored beads/gardenia+ } \\
\text { vs. clear beads/jasmine }\end{array}$ & $\begin{array}{l}\text { Colored beads/jasmine+ } \\
\text { vs. clear beads/gardenia }\end{array}$ & Terrycloth \\
\hline EDR & $\begin{array}{l}\text { Clear beads/gardenia+ } \\
\text { vs. colored beads/jasmine }\end{array}$ & $\begin{array}{l}\text { Clear beads/jasmine+ } \\
\text { vs. colored beads/gardenia }\end{array}$ & Terrycloth \\
\hline
\end{tabular}

on one dimension, e.g. odor, and disregard the other dimension, e.g. digging media. Alternate testing pairs would be cinnamon+/ light foam shapes versus patchouli/dark foam shapes and cinnamon+/dark foam shapes versus patchouli/light foam shapes. During the CDR the rat was reinforced for responding to previously unrewarded exemplar of a dimension, e.g. patchouli.

For the ID task, a new set of stimuli was introduced, but the same dimension that predicted reward in previous tests $(\mathrm{SD}, \mathrm{CD}$, CDR) was still rewarded (e.g. odor). Testing with novel sets of stimuli was hypothesized to facilitate the formation of an attentional set, e.g. focus on odor, when presented with new stimuli. Subjects that formed an attentional set should require the same or fewer trials to learn the ID than the CD. After the IDR, an additional novel set of stimuli was used for the ED shift.

The ED tests the ability of the subject to shift an attentional set. Rats, nonhuman primates and humans all require more trials to learn the ED than the ID $[11,14,15]$, which demonstrates the attentional set-shifting cost. On the ED task, the subjects were tested with 1 of 6 possible patterns of shifts between the relevant dimension in the ID and ED (texture to digging media, texture to odor, odor to digging media, odor to texture, digging media to texture, and digging media to odor). These were counterbalanced across subjects. In the ED, the previously unrewarded but variable attribute becomes paired with reinforcement, e.g. digging media, so that the rats were required to inhibit responding to the attentional set and learn a previously irrelevant attribute-predicted reward. After the ED, the rats were tested in the final reversal (EDR).

\section{Brain Activity Subjects and Metabolic Mapping with 2DG}

To evaluate regional brain activity as assessed by glucose uptake, 10 naive adult subjects -5 control $(25 / 25)$ and 5 prenatally malnourished $(6 / 25)$ - that were littermates of rats included in the behavioral experiment received an intraperitoneal injection of the metabolic activity marker 2DG (VWR/GE Healthsource, Radnor, Pa., USA) at a dose of $100 \mu \mathrm{Ci} / \mathrm{kg}$, (3700000 becquerel; specific activity =
$390 \mathrm{mCi} / \mathrm{mmol}$ or 14430000000 becquerel) on PND 100. After the injection, each animal was returned to their home cage for $45 \mathrm{~min}$ to allow the 2DG to be taken up in active brain structures [30]. The animals were then anesthetized with sodium pentobarbital $(65 \mathrm{mg} /$ $\mathrm{kg}$ ) to produce a deep surgical level of anesthesia and perfused through the heart with $250 \mathrm{ml}$ of fixative (2\% paraformaldehyde and $15 \%$ sucrose in $0.1 \mathrm{M}$ phosphate buffer, $\mathrm{pH} 7.4$ ) for $5 \mathrm{~min}$. The brains were immediately removed, coated with albumin and frozen at $-30^{\circ} \mathrm{C}$ in 2 -methylbutane for $30 \mathrm{~min}$ and stored at $-80^{\circ} \mathrm{C}$.

The brains were later removed and cut in 20 - $\mu$ m-thick coronal sections on a cryostat (Hacker Instruments, Inc., Fairfield, N.J., USA) at $-23^{\circ} \mathrm{C} ; 1$ out of every 5 sections was thaw-mounted on gelatin-chrome alum-subbed coverslips and rapidly dried on a warming plate. The coverslips were stored at $-20^{\circ} \mathrm{C}$ until sections for all subjects were available. They were then removed from the freezer and batch-processed by affixing them to Bristol board, and apposing them to high-resolution X-ray film (Structurix; Agfa, Belgium) with calibrated $14 \mathrm{C}$ microscales (Amersham, Piscataway, N.J., USA) and exposed at $-80^{\circ} \mathrm{C}$ for 10 days. The films were developed (Kodak D-19), washed and fixed.

These autoradiographs were digitized using imaging software (MCID; Imaging Research, St. Catherines, Ont., Canada), with constant illumination (Northern light illuminator) and flat field correction. The uptake of 2DG was assessed using the MCID system to measure calibrated optical densities in 5 gray matter regions of interest (ROIs): PrL, infralimbic cortex (IL), piriform cortex (Pir), ACC, OFC (shown in fig. 3), as well as the superior colliculus (SC; not shown). Gray matter ROI values were normalized relative to sectional white matter values acquired to reduce inter-sectional and inter-animal variability in 2DG uptake. Such an approach normalizes signals in light of small variations in dose, section thickness, development or exposure time [31] and has been widely used in 2DG experiments [31-34]. White matter adjacent to each gray matter ROI was also measured and used to normalize the gray matter values $[31,33]$. 
Data Analyses and Statistics

Behavioral Study. Weekly weights and rate of growth (g/week) were analyzed using a mixed-factor two-way ANOVA (nutrition $x$ week), with week as a repeated measure and nutrition as a between-subject factor. The postrestriction weights were recorded each week and assessed using a mixed-factor ANOVA of nutrition (2 levels) and weekly weight (4 levels). Because certain stages of the tasks assess unique cognitive demands and these cognitive processes are controlled by unique neural substrates, related subtests of the ID/ED (attentional set shifting) were analyzed using separate ANOVAs. The number of trials needed to reach criterion performance in the ID was compared to the ED in a mixed-factor ANOVA with the within-subject factor of test (2 levels) and the between-subject factor of nutrition group (2 levels). The number of trials to reach criterion on the SD and CD were analyzed using a mixed-factor ANOVA of test $\times$ nutrition. The number of trials to reach criterion on tests of reversal learning was assessed in a separate mixed-factor ANOVA with the within-subject factor of test (3 levels; CDR, IDR and EDR) and the between-subject factor of nutrition.

$2 D G$ Study. For the 2DG analyses, each subject's regional values were normalized to the respective white matter values. Then, a mixed-factor ANOVA was implemented using the between-subject factor of nutrition (2 levels) and the within-subject factors of hemisphere (2 levels) and region (6 levels). Contrasts of the least squares means (LSM) were used to determine differences between control and prenatally malnourished subjects for each brain region sampled.

\section{Results}

\section{Behavioral Subjects}

Overall, 1 rat from the $6 / 25$ group and 3 rats from the $25 / 25$ group failed to complete exemplar training, leaving 9 rats in the $6 / 25$ group and 14 in the $25 / 25$ group.

\section{Body Weight: before Restriction}

Figure 1 shows weight gain from birth through postnatal week 11 .

A repeated-measures ANOVA (nutrition $\times$ week) over weeks 1-11 confirmed that all rats continued to gain weight while food was restricted $\left(\mathrm{F}_{10,90}=569 ; \mathrm{p}<0.0001\right)$ in both nutritional groups. There was, however, a significant nutrition $\times$ week interaction $\left(\mathrm{F}_{10,90}=5.5 ; \mathrm{p}<0.01\right)$, because of a nutrition group difference at week $11\left(\mathrm{~F}_{1,9}=\right.$ 9.2; $\mathrm{p}<0.05$ ). The rate of growth (grams/day) was similar between the $6 / 25$ and $25 / 25$ rats over this 11 -week period, except on week 10-11 when the 25/25 rats had a higher rate of growth $\left(\mathrm{F}_{1,9}=11.65 ; \mathrm{p}<0.01\right)$. The average freefed weight on PND 90 for prenatally malnourished 6/25 subjects was $384.43 \pm 14.85$ (mean \pm SEM), while control $25 / 25$ rats weighed an average of $438.87 \pm 9.34 \mathrm{~g}\left(\mathrm{t}_{21}=\right.$ $-3.28 ; \mathrm{p}=0.004)$.

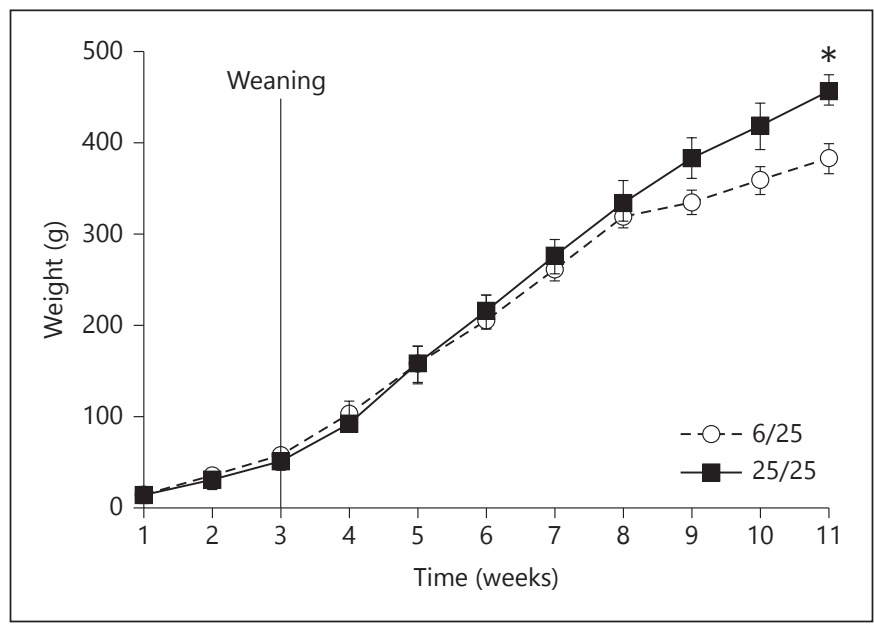

Fig. 1. Weight data prior to the onset of food restriction are shown in grams. These data were collected weekly. The prenatally malnourished rats $(6 / 25)$ were similar in weight to controls $(25 / 25)$ for the first 10 weeks, but weighed less than controls on week 11 as indicated by the asterisk. The vertical line at week 3 indicates weaning on PND 21.

\section{Body Weight: after Restriction}

Over the 4 weeks of food restriction, there was a significant change in weight (ANOVA), with the $6 / 25$ and $25 / 25$ groups converging (nutrition $\times$ week: $F_{5,105}=78.26$; $\mathrm{p}<0.001$ ). Planned t tests showed that the mean weights of each group were no longer different by week 2 of restriction (all $\mathrm{p}>0.05$ ).

\section{Formation and Shifting of Attentional Set}

All subjects required significantly more trials to reach criterion performance on the ED than the ID $\left(\mathrm{F}_{1,21}=\right.$ $18.72 ; \mathrm{p}<0.001)$. Planned comparisons revealed that $6 / 25$ rats were less able to shift attentional set, as they required more trials to reach criterion performance on the ED than the $25 / 25$ rats $\left(t_{21}=2.87 ; \mathrm{p}=0.009\right)$. They were not different from the well-nourished $25 / 25$ control subjects in the formation of the attentional set (ID: $t_{21}=1.45 ; \mathrm{p}>0.05$ ).

\section{Reversal Learning}

Overall, prenatally malnourished rats were less able to perform reversals than controls $\left(\mathrm{F}_{1,21}=7.60 ; \mathrm{p}=0.01\right.$; fig. 2). Despite the overall poorer performance of prenatally malnourished rats on reversal learning, there was no significant difference between the groups on any individual reversal test $\left(\mathrm{F}_{2,42}=0.3 ; \mathrm{p}>0.05 ;\right.$ fig. 1$)$. All subjects required more trials to reach criterion performance on the first reversal compared with subsequent reversals $\left(F_{2,42}=16.65 ; p=0.001\right)$. No other significant effects of prenatal malnutrition were found. 


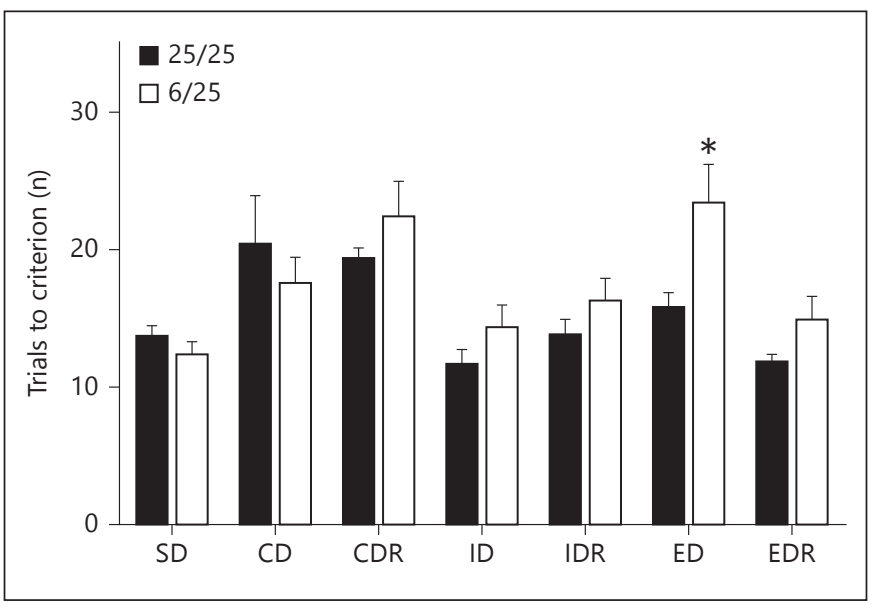

Fig. 2. Stages of attentional set-shifting task. Prenatally malnourished rats $(6 / 25, \mathrm{n}=9)$ were more cognitively rigid than control rats $(25 / 25, \mathrm{n}=14)$, as shown by the greater number of trials required to shift attentional set during the ED and indicated by the asterisk in the figure. This cognitive rigidity was not sufficient to provide an advantage in forming attentional set as tested by the ID task since rats exposed to both nutritional conditions performed equally well. All rats required more trials to reach criterion performance on the ED than the ID. ${ }^{*} \mathrm{p}<0.05$.

\section{Simple and Compound Discrimination}

Rats from both nutrition groups required more trials to reach criterion performance on trials when a second variable but irrelevant stimulus dimension was introduced, i.e. the $\mathrm{CD}\left(\mathrm{F}_{1,21}=5.35 ; \mathrm{p}=0.03\right)$. These data show that all rats were susceptible to the effects of the distracting dimension introduced at the CD stage of testing and could successfully perform conditional discriminations. These effects were the same regardless of nutritional history (nutrition: $\mathrm{F}_{1,21}=0.71 ; \mathrm{p}>0.05$; nutrition $\times$ test: $\mathrm{F}_{1,21}=0.1 ; \mathrm{p}>0.05$; fig. 1$)$.

\section{DG Results}

Of the 10 subjects, 2 rats in the 25/25 did not exhibit a radioactive brain signal indicating that $2 \mathrm{DG}$ was not reliably injected, leaving 3 subjects in this group. Results revealed no interhemispheric differences (hemisphere: $\left.\mathrm{F}_{1,6}=1.19 ; \mathrm{p}=0.3\right)$ and no significant interactions of hemisphere with any factor (all $\mathrm{p}>0.05$ ). Hence, data shown are the mean metabolic activity collapsed across hemisphere for each region (fig. 3, 4). Rats exposed to prenatal malnutrition had decreased metabolic activity (nutrition: $\mathrm{F}_{1,6}=6.88 ; \mathrm{p}=0.04$ ) which varied by subregion (nutrition $\times$ region: $\mathrm{F}_{5,30}=4.26 ; \mathrm{p}<0.03$ ).

As shown in figure 4, prenatal malnutrition was associated with decreased metabolic activity in all 4 prefrontal

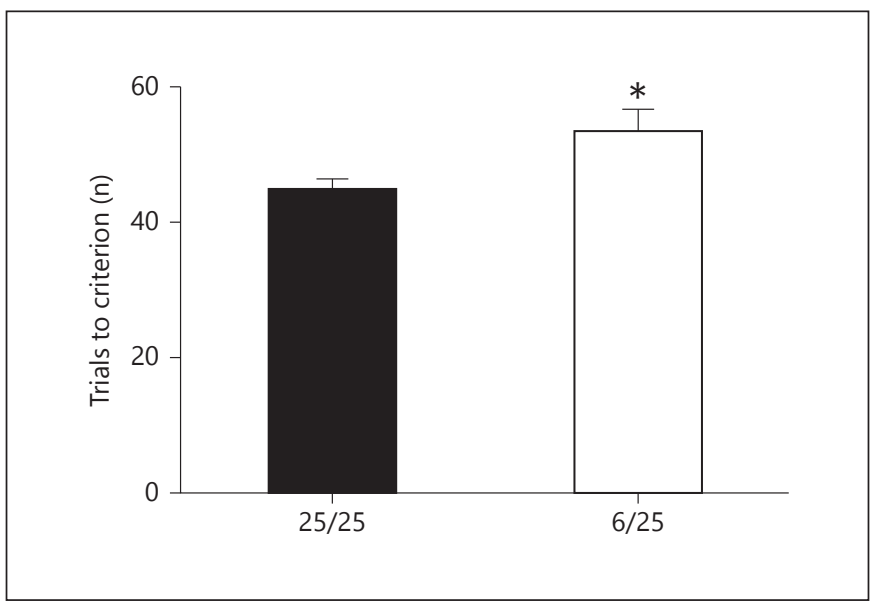

Fig. 3. Graph showing total performance (trials to criterion) across all reversals. Prenatally malnourished rats $(6 / 25, n=9)$ required more trials to learn reinforcement contingencies than control rats $(25 / 25, \mathrm{n}=14)$ as indicated by the asterisk. While performance did not differ on any individual tests of reversal learning, each reversal test showed the same pattern of impaired performance in the prenatally malnourished $6 / 25$ rats (as shown in fig. 1). ${ }^{*} \mathrm{p}<0.05$.

subregions (test of nutrition group differences using LSM showed all $\mathrm{p}<0.001$ for PrL, ACC and OFC and $\mathrm{p}<0.01$ for IL). These differences corresponded to a $27.02 \%$ decrease in the PrL, a $23.08 \%$ decrease in the IL, a $31.49 \%$ decrease in the ACC and a $23.42 \%$ decrease in the OFC when prenatally malnourished rats were compared to controls. In contrast, there was no significant effect of prenatal malnutrition on metabolic activity in the SC or Pir (LSM test: $\mathrm{p}=0.74$ and 0.89 , respectively).

\section{Discussion}

\section{Summary of Behavioral Findings}

The current study demonstrates that prenatal protein malnutrition results in significant impairments in attentional set-shifting abilities (impaired ED; fig. 2) and in reversal learning (total performance on CDR, IDR and EDR; fig. 3). However, prenatally malnourished and control subjects were equally proficient in learning conditional discriminations of both simple (SD) and complex stimuli (CD, ID) and were capable of disregarding irrelevant information (CD) and forming an attentional set (ID; fig. 2). Cognitive and emotional rigidity are known consequences of malnutrition during critical periods of brain development in the rat $[25,35,36]$. Moreover, im- 
Fig. 4. ROIs including the PrL, IL, ACC, OFC, and Pir were outlined according to Paxinos and Watson's atlas of the rat brain (2007).The OFC included both the ventral and lateral orbital cortices. Illustrative examples of 2DG uptake in prefrontal areas of a control rat $(25 / 25 ; \mathbf{a})$ and a prenatally malnourished rat $(6 / 25 ; \mathbf{b})$.

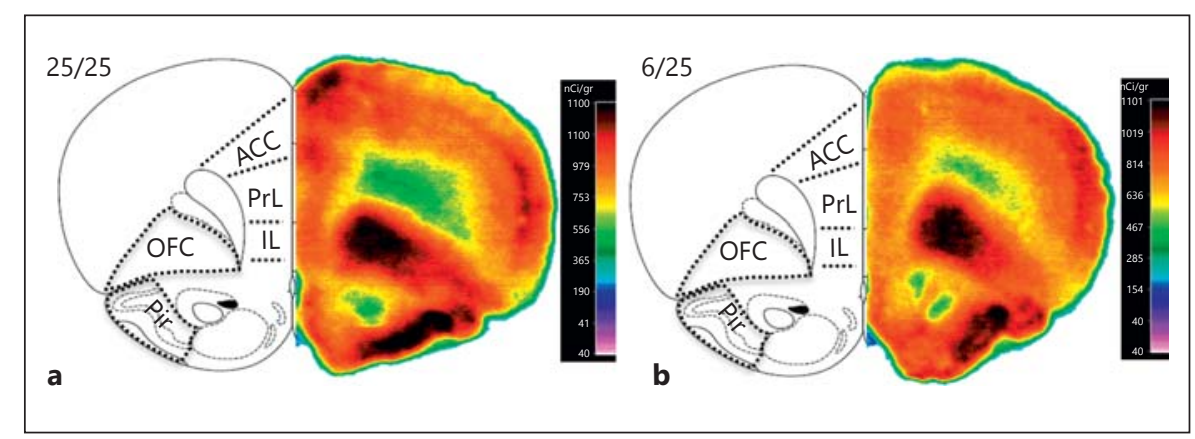

Fig. 5. Graph depicts the mean $( \pm$ SEM) 2DG uptake in the 6 ROIs: PrL, IL, ACC, OFC, and SC of prenatally malnourished $(6 / 25, \mathrm{n}=5)$ and control $(25 / 25, \mathrm{n}=3)$ rats. Each bar represents the regional mean optical density normalized to adjacent white matter. LSM tests comparing 2DG metabolic activity in the brains of prenatally malnourished $(6 / 25)$ vs. control $(25 / 25)$ rats show significant nutrition group differences on PrL, ACC, OFC (all p < 0.001), and IL $(\mathrm{p}<0.01)$, but not SC $(\mathrm{p}=0.74)$ or Pir (0.89). ${ }^{* *} \mathrm{p}<0.01$; $^{* * *} \mathrm{p}<0.001$.

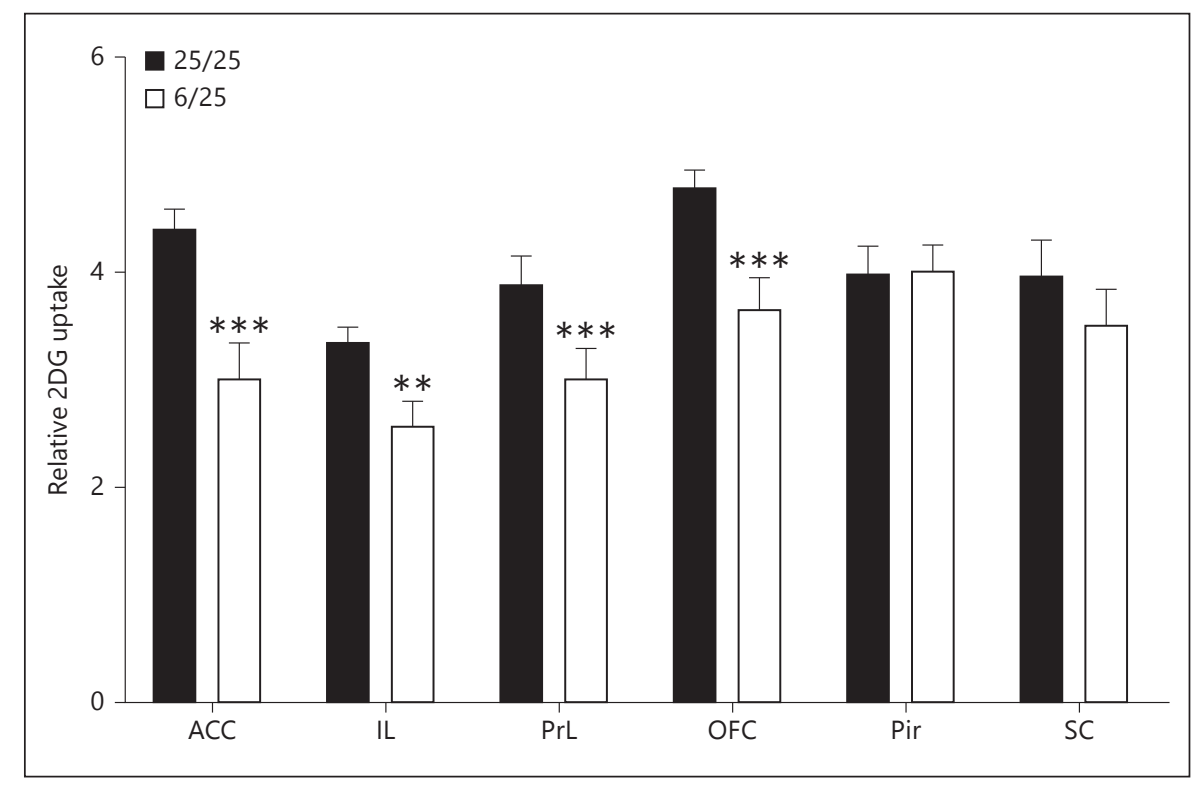

paired cognitive flexibility has also been reported in other animal models of prenatal malnutrition, including sheep [37]. These data do not reflect a gross attentional impairment as data gathered from additional male littermates showed no effect on sustained attention (McGaughy, unpublished data).

\section{Summary of 2DG Activity Mapping}

Using 2DG to explore the possible neuroanatomical substrates of these behavioral impairments, we found that prenatal protein malnutrition produces specific functional alterations in 2DG uptake in the rat PFC: the PrL, IL, ACC, and OFC. However, there was no difference in 2DG uptake in the SC, a nonlimbic and nonprefrontal area, or in the Pir (fig. 5). These data support the hypothesis that changes in metabolic activity in PFC subregions reflect a specific vulnerability to prenatal malnutrition and not a generalized effect on brain activity.
Executive Function and Neuromodulators in PFC

Impairments in attentional set shifting result from damage to the PrL in the rat $[15,28,29]$ or to the dorsolateral PFC in humans [11] and nonhuman primates [13, 14]. Specifically, damage to the noradrenergic afferents to the PrL impairs ED performance but does not affect performance on any other stage of the attentional set-shifting task $[28,38]$. The reduction in the 2DG signal in prefrontal regions in prenatally malnourished rats may reflect a change in synaptic density restricted to the prefrontal cortex, a change in the functional status of extant synapses, or both. In studies of littermates of this subject cohort, we have found that malnutrition decreases cortical norepinephrine fibers and extracellular concentrations of norepinephrine as determined by in vivo microdialysis in the PrL (Mokler, unpubl. data). These findings are in line with prior work showing that early life malnutrition impacts the development of the locus coeruleus [39-41], the 
nuclei from which noradrenergic cortical afferents originate. As a result, we hypothesize that decreased metabolic activity in the PrL reflects hypofunction of norepinephrine, leading to cognitive rigidity. Future studies may be aimed at determining the efficacy of drugs that increase cortical norepinephrine in remediating these cognitive deficits.

There was a main effect of nutrition on total reversal learning but no difference on any single test of reversal learning, e.g. the CDR, IDR or EDR. Tests of reversals using complex stimuli such as those tested in the present task have been shown to be sensitive to damage to the ACC [20] or the OFC [22]. Reversal learning requires monoaminergic inputs to the lateral OFC, with evidence to support the involvement of serotonin [42], dopamine [43] and norepinephrine [44]. Previous work by Barbelivien et al. [23] (2001) has found that lower metabolic activity in the ACC was present in subjects with poor impulse control. The present study cannot determine whether the reversal learning impairments found in the prenatally malnourished subjects reflect problems in impulse control or rigidity in maintaining prior reinforcement contingencies. Future studies will be aimed at addressing these questions. Importantly, prenatal protein restriction produces impairments in some, but not all, stages of the attentional set-shifting task. Findings from this study also indicate that malnutrition-related deficits do not result from gross impairments in attention, learning or memory. The ED and tests of reversal learning appear to be sensitive indices of early and enduring brain changes induced by prenatal malnutrition. Hence this paradigm may be particularly useful in further studies of the underlying neurobiological changes associated with this condition.

\section{Effects of Prenatal Malnutrition on Brain Structure and Function}

Early reports on the effects of perinatal protein malnutrition on the anatomical development of the brain [45] showed a decrease in synaptic spine density [46] and reduced dendritic length for some, but not all, dendritic processes in the brain of 30-day-old rats [47]. Furthermore, prenatal malnutrition reduces cell numbers in specific subfields of the hippocampus [48], but there is no widespread change in numbers of neurons in the medial PFC (Rosene, unpubl. data). Although we have documented changes in the neuroanatomy and neurophysiology of the hippocampus, performance on the Morris Maze (a classic test of hippocampal function) is not impaired in the prenatally malnourished rats relative to controls [49]. The attentional set-shifting task was developed to be more sensitive to frontal lobe damage than damage in other brain regions. The use of the total changeover design was hypothesized to decrease proactive interference during the task and minimize the involvement of the medial temporal lobe in the task $[10,11]$.

Finally, prenatal malnutrition not only impacts the developing fetus, but could also alter the rate of growth and development of young pups postnatally. This is important because accelerating growth in the postnatal period in prenatally malnourished rodents is known to result in a shortened life span and increased susceptibility to obesity $[51,52]$ and can also potentially impact brain development. However, in our model of prenatal protein deficiency, there was no evidence of an accelerated rate of weight gain in the $6 / 25$ prenatally malnourished rats relative to $25 / 25$ control pups during the 3 -week litter period or after weaning.

\section{Effects of Nutritional Deficiencies in Human \\ Populations}

The deficits reported here parallel findings in human populations. Attention deficits have been reported in studies of early childhood malnutrition in Jamaica [53, 54]. Increased attention deficits were also present in Barbadian schoolchildren and adolescents who suffered from a restricted period of malnutrition in the first year of life (a critical period of brain development) and subsequently enrolled in an intervention program that provided nutrition education, subsidized food, home visits and medical care $[4,5]$. Despite complete catch-up in growth by the end of adolescence [55], attention deficits persisted up to 40 years of age and were not attributable to continuing malnutrition, low IQ or home environmental factors [6]. In adulthood, the BRIEF and WCST [7] were used to document set shifting in this same cohort and confirmed malnutrition-related deficits on measures of cognitive flexibility and concept formation. The malnutrition-associated deficits in performance on the WCST were of particular interest, not only because of striking parallels to the current findings but because functional neuroimaging studies have confirmed a significant role of the PFC on this task. Recent neuroimaging studies demonstrate a distributed network, primarily the PFC, but also the inferior parietal lobe, temporoparietal association cortex and visual cortex, as well as the basal ganglia [56]. Monchi et al. [57] (2001) identified two distinct circuits underlying WCST performance: a distributed network involving mid-dorsolateral PFC associated with receiving positive or negative feedback, and a second network involving mid-ventro- 
lateral PFC associated with negative feedback and thus the need to shift. These findings further implicate a relationship between pre- and postnatal malnutrition and the development of the PFC and associated functional networks.

\section{Summary and Conclusions}

This study demonstrates that prenatal malnutrition in a well-described animal model produces deficits in tests of attentional set shifting and reversal learning, similar to findings reported in humans exposed to early childhood malnutrition.

Moreover, the same insult impairs metabolic activity in prefrontal circuits critical to these behaviors. This study extends our earlier report that showed altered activation of the ACC and adjacent medial PFC in prenatally malnourished rats as a result of restraint stress, using $\mathrm{cFos}$ as the activation marker [16]. These results suggest that the cognitive circuits of the medial PFC (PrL and IL), as well as the ACC and OFC, are particularly vulnerable to prenatal protein malnutrition. Future studies will be aimed at better understanding the mechanisms of this selective vulnerability and are expected to provide insight into the full impact of prenatal malnutrition on brain function.

\section{Acknowledgments}

The authors wish to thank Andrew T. Bates for excellent technical assistance, Sarah Bradshaw for her help in editing earlier drafts of this manuscript and Garrett Fitzmaurice and Laura Fischer for their assistance with statistical analyses. This research was supported by NIH grants MH074811 (J.R.G.) and HD060986 (J.R.G.).

\section{References}

1 UNICEF-WHO-World Bank Joint child mal- 10 Owen AM, et al: Contrasting mechanisms of nutrition estimates, 2012. New York, UNICEF, Geneva, WHO, Washington, World Bank, 2012.

-2 Grantham-McGregor S, et al: Developmental potential in the first 5 years for children in developing countries. Lancet 2007;369:60-70.

3 Galler JR, Ross R: Malnutrition and mental development; in Suskind R, Lewinter-Suskind L (eds): Textbook of Pediatric Nutrition. Elk Grove Village, American Academy of Pediatrics, 1993, pp 173-179.

4 Galler JR, et al: The influence of early malnutrition on subsequent behavioral development. II. Classroom behavior. J Am Acad Child Psychiatry 1983;22:16-22.

5 Galler JR, et al: The long-term effects of early kwashiorkor compared with marasmus. IV. Performance on the national high school entrance examination. Pediatr Res 1990;28:235239.

6 Galler JR, et al: Infant malnutrition is associated with persisting attention deficits in middle adulthood. J Nutr 2012;142:788-794.

7 Waber DP, et al: Neuropsychological outcomes at mid-life following moderate to severe malnutrition in infancy. Neuropsychology 2014;28:530-540.

8 Mohamed WM, et al: Methylphenidate improves cognitive deficits produced by infantile iron deficiency in rats. Behav Brain Res 2011;216:146-152.

-9 Lukowski AF, et al: Iron deficiency in infancy and neurocognitive functioning at 19 years: evidence of long-term deficits in executive function and recognition memory. Nutr Neurosci 2010;13:54-70 impaired attentional set-shifting in patients with frontal lobe damage or Parkinson's disease. Brain 1993;116:1159-1175.

11 Owen AM, et al: Extra-dimensional versus intra-dimensional set-shifting performance following frontal lobe excisions, temporal lobe excisions or amygdalohippocampectomy in man. Neuropsychologia 1991;29:9931006.

12 Robbins TW, et al: A study of performance on tests from the CANTAB battery sensitive to frontal lobe dysfunction in a large sample of normal volunteers: implications for theories of executive function and cognitive aging. Cambridge Neuropsychological Test Automated Battery. J Int Neuropsychol Soc 1998; 4:474-490,

13 Dias R, Robbins TW, Roberts AC: Dissociation in prefrontal cortex of affective and attentional shifts. Nature 1996;380:69-72.

14 Dias R, Robbins TW, Roberts AC: Dissociable forms of inhibitory control within prefrontal cortex with an analog of the Wisconsin card sort test: restriction to novel situations and independence from 'on-line' processing. J Neurosci 1997; 17:9285-9297.

15 Birrell JM, Brown VJ: Medial frontal cortex mediates perceptual attentional set shifting in the rat. J Neurosci 2000;20:4320-4324.

16 Rosene DL, et al: Prenatal protein malnutrition in rats alters the c-Fos response of neurons in the anterior cingulate and medial prefrontal region to behavioral stress. Nutr Neurosci 2004;7:281-289.

$\checkmark 17$ Flores $\mathrm{O}$, et al: Hidden prenatal malnutrition in the rat: role of $\beta_{1}$-adrenoreceptors on syn- aptic plasticity in the frontal cortex. J Neurochem 2011;119:314-323.

18 Galler JR, Shumsky JS, Morgane PJ: Malnutrition and brain development; in W.A. Walker WA, Watkins JB (eds): Nutrition in Pediatrics: Basic Science and Clinical Application. Neuilly-sur-Seine, Decker Europe, 1996, pp 196-212.

19 Lister JP, et al: Prenatal protein malnutrition alters the proportion but not numbers of parvalbumin-immunoreactive interneurons in the hippocampus of the adult Sprague-Dawley rat. Nutr Neurosci 2011; 14:165-178.

20 Newman LA, McGaughy J: Attentional effects of lesions to the anterior cingulate cortex: how prior reinforcement influences distractibility. Behav Neurosci 2011;125:360-371.

$21 \mathrm{Ng}$ CW, et al: Double dissociation of attentional resources: prefrontal versus cingulate cortices. J Neurosci 2007;27:12123-12131.

22 McAlonan K, Brown VJ: Orbital prefrontal cortex mediates reversal learning and not attentional set-shifting. Behav Brain Res 2003; 146:97-103.

23 Barbelivien A, Ruotsalainen S, Sirvio J: Metabolic alterations in the prefrontal and cingulate cortices are related to behavioral deficits in a rodent model of attention-deficit hyperactivity disorder. Cereb Cortex 2001;11:1056-1063.

24 Resnick O, Morgane PJ: Animal models for small-for-gestational age (SGA) neonates and infants-at-risk (IAR). Brain Res 1983;312: 221-225.

25 Tonkiss J, Galler JR: Prenatal protein malnutrition and working memory performance in adult rats. Behav Brain Res 1990;40:95-107. 
26 Tonkiss J, et al: Fetal protein malnutrition impairs acquisition of a DRL task in adult rats. Physiol Behav 1990;48:73-77.

-27 Galler JR, Tonkiss J: Prenatal protein malnutrition and maternal behavior in SpragueDawley rats. J Nutr 1991;121:762-769.

28 Newman LA, Darling J, McGaughy J: Atomoxetine reverses attentional deficits produced by noradrenergic deafferentation of medial prefrontal cortex. Psychopharmacology 2008; 200:39-50.

29 Newman LA, McGaughy J: Cholinergic deafferentation of prefrontal cortex increases sensitivity to cross-modal distractors during a sustained attention task. J Neurosci 2008;28: 2642-2650.

30 Sokoloff L, et al: The ${ }^{14} \mathrm{C}$-deoxyglucose method for the measurement of local cerebral glucose utilization: theory, procedure, and normal values in the conscious and anesthetized albino rat. J Neurochem 1977;28:897-916.

- 31 Sharp FR, et al: The relationship of local cerebral glucose utilization to optical density ratios. Brain Res 1983;263:97-103.

-32 Duncan GE, Johnson KB, Breese GR: Topographic patterns of brain activity in response to swim stress: assessment by 2-deoxyglucose uptake and expression of Fos-like immunoreactivity. J Neurosci 1993;13:3932-3943.

33 Rushmore RJ, Payne BR, Lomber SG: Functional impact of primary visual cortex deactivation on subcortical target structures in the thalamus and midbrain. J Comp Neurol 2005; 488:414-426

34 Jablonka JA, et al: Remapping of the somatosensory cortex after a photothrombotic stroke: dynamics of the compensatory reorganization. J Neurosci 2010;165:90-100.

- 35 Strupp BJ, Levitsky DA: Enduring cognitive effects of early malnutrition: a theoretical reappraisal. J Nutr 1995;125:2221S-2232S.

36 Laus MF, et al: Early postnatal protein-calorie malnutrition and cognition: a review of human and animal studies. Int J Environ Res Public Health 2011;8:590-612.
37 Erhard HW, et al: Effects of prenatal undernutrition on emotional reactivity and cognitive flexibility in adult sheep. Behav Brain Res 2004;151:25-35.

38 Tait DS, et al: Lesions of the dorsal noradrenergic bundle impair attentional set-shifting in the rat. Eur J Neurosci 2007;25:3719-3725.

39 Pinos H, et al: Early undernutrition decreases the number of neurons in the locus coeruleus of rats. Nutr Neurosci 2006;9:233-239.

40 Pinos $\mathrm{H}$, et al: Undernutrition and food rehabilitation effects on the locus coeruleus in the rat. Neuroreport 2004;28:1417-1428.

41 Diaz-Cintra S, et al: The Effects of protein deprivation on the nucleus locus coeruleus: a morphometric Golgi study in rats of three age groups. Brain Res 1984;304:243-253.

42 Furr A, Lapiz-Bluhm MD, Morilak DA: $5-\mathrm{HT}_{2 \mathrm{~A}}$ receptors in the orbitofrontal cortex facilitate reversal learning and contribute to the beneficial cognitive effects of chronic citalopram treatment in rats. Int J Neuropsychopharmacol 2012;15:1295-1305.

43 Clarke HF, et al: Dopamine, but not serotonin, regulates reversal learning in the marmoset caudate nucleus. J Neurosci 2011;31: 4290-4297.

44 Seu E, et al: Inhibition of the norepinephrine transporter improves behavioral flexibility in rats and monkeys. Psychopharmacology 2009;202:505-518.

45 Crnic LS, Chase HP: Models of infantile undernutrition in rats: effects on brain lipids. Dev Neurosci 1980;3:49-58.

46 Salas M: Effects of early undernutrition on dendritic spines of cortical pyramidal neurons. Dev Neurosci 1980;3:109-117.

47 West CD, Kemper TL: The effect of a low protein diet on the anatomical development of the rat brain. Brain Res 1976;107:221-237.
48 Lister JP, et al: Effect of prenatal protein malnutrition on numbers of neurons in the principal cell layers of the adult rat hippocampal formation. Hippocampus 2005;15:393403 .

49 Tonkiss J, Shultz P, Galler JR: An analysis of spatial navigation in prenatally protein malnourished rats. Physiol Behav 1994;55:217224

50 Sahakian BJ, et al: Sparing of attentional relative to mnemonic function in a subgroup of patients with dementia of the Alzheimer's type. Neuropsychologia 1990;28:1197-1213.

51 Alexandre-Gouabau MC, et al: Postnatal growth velocity modulates alterations of proteins involved in metabolism and neuronal plasticity in neonatal hypothalamus in rats born with intrauterine growth restriction. J Nutr Biochem 2012;23:140-152.

52 Ozanne SE, Hales CN: Lifespan: catch-up growth and obesity in male mice. Nature 2004;427:411-412.

53 Richardson SA, Birch HG: School performance of children who were severely malnourished in infancy. Am J Ment Defic 1973; 77:623-632.

54 Walker SP, et al: Early childhood stunting in associated with poor psychological functioning in late adolescence and effects are reduced by psychosocial stimulation. J Nutr 2007;137: 2464-2469.

55 Galler JR, et al: Long-term effects of early kwashiorkor compared with marsmus. I. Physical growth and sexual maturation. J Pediatr Gastroenterol Nutr 1987;6:841-846.

56 Nyhus E, Barcelo F: The Wisconsin Card Sorting Test and the cognitive assessment of prefrontal executive functions: a critical update. Brain Cogn 2009;71:437-451.

57 Monchi O, Petrides M, Petre V, Worsley K, Dagher A: Wisconsin Card Sorting revisited: distinct neural circuits participating in different stages of the task identified by event-related functional magnetic resonance imaging. J Neurosci 2001;21:7733-7741. 